\title{
Resíduos agroindustriais como substrato para cultivo indoor de cogumelos comestíveis da espécie pleurotus ostreatus
}

\author{
Pedro Ítalo Alves de Carvalho ${ }^{\mathfrak{} \odot}$, Maria Rebeca Brandão Sales ${ }^{a} \oplus$, Jaime Conrado Aragão Neto ${ }^{a}$, \\ Francisco Valdicélio Ferreira ${ }^{b *}$ (1) \\ ${ }^{a}$ Centro Universitário Inta (UNINTA), Brasil \\ b Universidade Federal do Ceará, Brasil \\ *Autor correspondente (celionutri@gmail.com)
}

\section{N F O}

\section{Keyworks}

Agaricaceae

Pleurotus

culture media

conditioned

mycelium

\begin{abstract}
A B S T R A C T
Agro-industrial waste as a substrate for indoor cultivation of edible mushrooms of the species pleurotus ostreatus. Mushrooms are defined as macrofungi belonging to the Fungi kingdom and phylum Basidiomycota whose main function is the decomposition of organic matter. In addition to their ecological function, these are considered as foods of high nutritional and medicinal value. According to the above, we aim here to standardize the indoor cultivation of edible mushrooms of the Pleurotus ostreatus Branco (POB) and Pleurotus ostreatus Preto (POP) strains with the use of agro-industrial residues (sugarcane bagasse and wood shavings) as a substrate. The results showed that substrate colonization differs as to the type of packaging and the amount of substrate. It was observed that the cultivation containing substrate (1:1) in reusable glass bottles showed higher standardization and quality when compared to the use of polypropylene bags, besides presenting greater culture homogeneity between strains. The POP strain showed $14 \%$ productivity and $16.47 \%$ biological efficiency, when compared to the POB strain which obtained $12 \%$ productivity and $14.11 \%$ biological efficiency. It was concluded that the technique was satisfactory since $P$. ostreatus productivity is directly linked to substrate quality, however, the use of controlled temperatures may favor the best yield and biological efficiency.
\end{abstract}

\section{R E S U M O}

Cogumelos são definidos como macrofungos pertencentes ao reino Fungi e filo Basidiomycota que tem como principal função a decomposição da matéria orgânica. Além de sua função ecológica, estes são considerados como alimentos de elevado valor nutricional e medicinal. De acordo com o exposto, objetivamos aqui padronizar o cultivo indoor de cogumelos comestíveis das linhagens de Pleurotus ostreatus Branco (POB) e Pleurotus ostreatus Preto (POP) com a utilização de resíduos agroindustriais (bagaço de cana-de-açúcar e raspas de madeira) como substrato. Os resultados obtidos demonstraram que a colonização do substrato difere quanto ao tipo de acondicionamento e a quantidade de substrato. Foi observado que o cultivo contendo substrato em razão de (1:1) em frascos de vidro reutilizáveis evidenciou maior padronização e qualidade quando comparadas à utilização de sacos de polipropileno, além de apresentar maior homogeneidade da cultura entre as linhagens. A linhagem de POP apresentou produtividade de $14 \%$ e eficiência biológica de $16,47 \%$, quando comparada a linhagem de POB que obteve produtividade de $12 \%$ e eficiência biológica de $14,11 \%$. Concluiu-se que a técnica foi satisfatória visto produtividade de $P$. ostreatus está diretamente ligada a qualidade de substrato, contudo, a utilização de temperaturas controladas pode favorecer ao melhor rendimento e eficiência biológica.

\section{Palavras-chaves}

Agaricaceae

meio de cultivo

condicionado

micélio 


\section{INTRODUÇÃO}

Os fungos representantes do gênero Pleurotus pertencem à ordem Agaricales, e são conhecidos pela grande variedade de sua morfologia (Lopes e Rosso, 2013). Estes estão dentre os fungos degradadores de madeira destacados como causadores da podridão-branca, por serem organismos mais efetivos quanto à biodegradação dos materiais lignocelulósicos na natureza, devido a síntese de enzimas oxidativas capazes de degradar os constituintes primários da madeira (Machuca e Ferraz, 2001). A presença de enzimas com capacidade de degradação de resíduos lignocelulósicos, incrementam a disponibilidade de assimilação via hifa e posteriormente distribuído dentro do organismo, as quais proporcionam a obtenção de compostos como carbono e nitrogênio para o seu crescimento (Alexandrino et al., 2007).

A maioria dos cogumelos comestíveis originários de fungos apresentam índices relevantes de desenvolvimento micelial em diversos tipos de matéria-prima enriquecidos ou não com farelos de cereais (Eira, 2004; SalesCampos et al., 2008). Geralmente os substratos utilizados para o cultivo de cogumelos são gramíneas secas, além de resíduos agrícolas como polpa de café, sabugo de milho e bagaço de cana de açúcar (Moda et al., 2005). Pleurotus é um cogumelo comestível de grande interesse biotecnológico devido à sua habilidade em degradar inúmeros resíduos agrícolas e sua alta qualidade sensorial (Sánchez, 2017).

Segundo Burgi (1995), cada tonelada de cana de açúcar moída gera $300 \mathrm{~kg}$ de bagaço de cana. O plantio da cana de açúcar no Ceará representa pouca expressividade comparado ao cenário nacional, porém possui impacto econômico significativo no mercado local com a extração do caldo de cana, tornando o bagaço de cana muitas vezes inutilizado. De acordo com Pelizer et al, (2007), a reutilização deste resíduo representa a otimização da produção agrícola, já que reduz o desperdício ao canalizá-los de volta para o processo econômico, e propicia a redução do seu volume, eliminando um possível impacto ambiental.

Atualmente, no Brasil, o cultivo e consumo de cogumelos do gênero Pleurotus tem aumentado de modo acentuado em função de vários fatores como a comercialização por seu valor gastronômico e devido a suas propriedades nutricionais, além de sua capacidade adaptativa à condição brasileira de clima tropical (Furlani e Godoy, 2007).

Diante da possibilidade de reutilização do bagaço de cana, componente rico em resíduos lignocelulósicos, o qual apresenta potencial de biotransformação a partir de seus constituintes, sendo eles principalmente, celulose, hemicelulose e lignina, como substrato para obtenção de corpos frutíferos (Menezes e Barreto, 2015).

Os cogumelos do gênero Pleurotus contém baixo teor de gordura e são ricos em proteínas, fibras, carboidratos, vitaminas, aminoácidos, e minerais como cálcio, potássio, iodo e fósforo, assim representando uma ótima alternativa de nutrição (Cheung, 2010). No entanto, essa composição depende do tipo de substrato, das metodologias de cultivo e das espécies cultivadas (Furlani e Godoy, 2007).

Estudos concluem ainda que estes macrofungos possuem propriedades medicinais passiveis de utilização na alimentação humana, indicando possíveis usos como antidiabéticos, antimicrobianos, antitumorais, anti-inflamatórios, moduladores do sistema imune e antioxidantes, desta forma, os cogumelos do gênero Pleurotus desempenham potencial de transformação de resíduos em alimentos com valor nutricional, gastronômico e medicinal agregados, aproveitando resíduos agrícolas que não estão diretamente disponíveis para o consumo humano, restituindoos em alimentos e o tornando mais acessível às populações em geral (Chang e Miles, 2004; Fernandes et al., 2015; Sánchez, 2017).

A busca por alternativas sustentáveis no âmbito alimentar que circundam práticas que promovam à alimentação saudável, visando obter a partir de resíduos madeireiros e agrícolas um alimento com alto valor nutricional com baixo custo, cultivo acessível, norteou e delineou as vertentes para elaboração do estudo. A Partir disso objetivamos aqui padronizar o cultivo indoor de cogumelos comestíveis das linhagens de Pleurotus ostreatus Branco (POB) e Pleurotus ostreatus Preto (POP) com a utilização de resíduos agroindustriais (bagaço de cana-de-açúcar e raspas de madeira) como substrato.

\section{MATERIAL E MÉTODOS}

\section{Local da pesquisa e Matriz primária}

Pesquisa de caráter experimental quantitativa realizada no Laboratório de Pesquisa Multiusuário do Centro Universitário INTA - UNINTA. A matriz primária corresponde a cepa de $P$. ostreatus que foi obtida em placa de petri em meio de cultura Batata Dextrose Ágar - BDA (micélio) e esporo em cultura liquida, adquirida de fonte comercial.

\section{Veículo para a Produção de Semente (Spawn)}

As sementes de sorgo (Sorghum bicolor) foram adquiridas comercialmente e utilizadas como 
substrato para o crescimento do fungo na quantidade de $500 \mathrm{~g}$, lavados em água corrente e levados à cocção durante 45 minutos em água destilada na razão de $1 / 2: 1 \mathrm{~m} / \mathrm{v}$. Após sua secagem, foram envasados $300 \mathrm{~g}$ de sorgo em frascos de vidro reutilizáveis com $550 \mathrm{ml}$ de volume, fechados com tampa de aço perfurada e preenchida com algodão. Posteriormente foram destinados a esterilização em autoclave vertical a $121 \pm 1{ }^{\circ} \mathrm{C}$ por 30 minutos.

Realizada a esterilização e o posterior resfriamento dos frascos a temperatura de $25{ }^{\circ} \mathrm{C}$ realizou-se a inoculação de $05 \mathrm{ml}$ de esporo $P$. ostreatus em cada frasco de sementes em câmara de fluxo laminar e ambiente estéril. Logo após a inoculação as sementes foram destinadas a sala escura, em ar ambiente com humidade de 70 a $80 \%$ e temperatura média de $36^{\circ}$ objetivando adaptação e assimilação das hifas à semente e assim obter o total crescimento micélio, período este compreendido em aproximadamente 40 dias, em condições estacionárias. Estes grãos colonizados foram denominados de semente ou Spawn.

\section{Ajuste e formulação de substrato}

Utilizaram-se substratos de cultivo que atendessem as expectativas de bom desenvolvimento e a disponibilidade dos resíduos locais. Comparando-se as diversas combinações de meios de cultivo, foi possível verificar que tanto a presença de sulfato de cálcio (CaSO4. $0,5 \mathrm{H} 2 \mathrm{O})$ e calcário dolomítico $(\mathrm{CaCO} 3 . \mathrm{MgCO} 3)$ com bagaço-de-cana mostraram-se essenciais para o desenvolvimento dos fungos.

Os resíduos agrícolas utilizados como matériaprima na produção dos substratos foram escolhidos em função da disponibilidade local e consistiram em bagaço da cana de açúcar e raspas de madeira. Coletados no mercado central e marcenarias locais pertencentes ao município de Sobral-CE, respectivamente.

O substrato utilizado para padronização da técnica de cultivo foi constituído a partir da proporção de 1:1 (bagaço da cana-de-açúcar: raspas de madeira) de ambos resíduos na quantidade de $05 \mathrm{~kg}$ respectivamente. $\mathrm{O}$ bagaço da cana-de-açúcar foi processado em forrageira visando diminuir a desintegração das fibras pertencentes à cana-de-açúcar, objetivando facilitar a assimilação das hifas da semente de Spawn ao substrato. Posteriormente, o substrato processado foi tratado com $1 \%$ calcário dolomítico e $1 \%$ gesso (100g de cada) e misturados. Após a homogeneização do substrato, umedeceu-se com água.

Atribuiu-se como recipiente para o cultivo frascos de vidro reutilizáveis que compreendem $220 \mathrm{ml}$ de volume $(13 \mathrm{~cm}$ de altura por $6 \mathrm{~cm}$ de comprimento) com tampa de aço. O substrato homogeneizado foi separado em 30 frascos com $200 \mathrm{~g}$ de substrato. As tampas de aço foram perfuradas ao centro e preenchidas com algodão para permitir as trocas gasosas. Em seguida, os frascos foram esterilizados a $121 \pm 1{ }^{\circ} \mathrm{C}$ durante 60 minutos, tempo este utilizado com intuito de maior esterilização do substrato e aumentar o rendimento favorecendo a adesão do fungo ao substrato, e resfriado em temperatura ambiente por 24 horas.

Utilizou-se também sacos plásticos novos de polietileno com capacidade máxima de $20 \mathrm{l}$, de baixa densidade, incolor, translucido para fins de cultivo. O qual possibilitou maior volume de utilização de substrato, este foi adaptado em caráter comparativo para diferentes faixas de crescimento, com quantitativo de substrato em sacos contendo 10, 5 e $2 \mathrm{~kg}$ de substrato. Foram atribuídos a todos os recipientes os mesmos critérios de processamento descritos anteriormente.

\section{Inoculação}

Após resfriamento, em condições assépticas, procedeu-se a inoculação no substrato transferindo $10 \mathrm{~g}$ do Spawn para os frascos de produção. Ao final da inoculação, todos os frascos foram identificados em gênero e data de inoculação. Posteriormente, destinados à incubação em sala fechada sob temperatura controlada artificialmente a $25^{\circ} \mathrm{C}$ e ausência de luz até completa colonização. Atribuiu-se as mesmas técnicas de montagem de substrato para a utilização dos sacos de polietileno, com quantidades diferente de substrato correspondem a 2,5 e $10 \mathrm{~kg}$.

\section{Incubação e frutificação}

A incubação dos frascos contendo as linhagens de Pleurotus ostreatus branco (POB) e Pleurotus ostreatus preto (POP) foi realizada na ausência de luz em câmara escura para prevenção de frutificação precoce. Os mesmos foram incubados em temperatura ambiente em torno de $25^{\circ} \mathrm{C}$ durante 30 dias. Quando os substratos dos frascos estavam totalmente colonizados, foram dispostos em temperatura ambiente ha $25^{\circ} \mathrm{C}$ e umidade relativa do ar acima de $80 \%$, através da utilização de umidificador de ar portátil (Lenoxx-Pua715) para obtenção de corpos frutíferos.

A colheita ocorreu de forma diária em até três dias após o início da frutificação com o intuito de evitar a desidratação destes resultando na perda de peso. A mesma se deu a partir da torção dos cachos evidenciados de forma manual. Após a colheita todos os cogumelos que emergiram de 
cada vaso foram pesados assepticamente $\mathrm{e}$ quantificados para o cálculo da Eficiência Biológica (EB) e percentagem de produtividade (P).

\section{Produtividade em massa fresca}

Foram realizados cálculos de eficiência biológica (EB) e Percentagem de produtividade (P) para expressar a produção da biomassa fúngica, caracterizada pela conversão dos resíduos lignocelulósicos em basidiomas (cogumelos). Este parâmetro é o mais utilizado pelos pesquisadores da área (Chang e Miles, 2004), o que facilita a comparação dos resultados com dados da literatura:

$$
\begin{aligned}
& \text { EB }(\%)=\frac{\text { Massa fresca de cogumelos }(\mathrm{g}) \times 100}{\text { Peso seco de substrato inicial }(\mathrm{g})} \\
& \mathrm{P}(\%)=\frac{\text { Massa fresca dos cogumelos }(\mathrm{g}) \times 100}{\text { Peso úmido de substrato inicial }(\mathrm{g})}
\end{aligned}
$$

\section{Análise de dados}

Utilizou-se o software GraphPad Prism 5.0 (GraphPad Software Inc., La Jolla, CA, USA) os dados foram apresentados como média e desvio padrão de $(n=15)$.

\section{RESULTADOS E DISCUSSÃO}

Em relação à diferença do crescimento micelial do mesmo tratamento, não houve diferencial estatístico entre EB dos spawns. Bettin et al., (2010), concluiu que concentrações de $0,5 \%$ de glicose auxiliam na assimilação do fungo ao meio de cultivo, ocorrendo melhoria referente a colonização do spawn. Entretanto, na técnica utilizada, apesar de não empregar a suplementação de nutrientes junto a semente, o fungo apresentou boa atividade de assimilação mesmo em ausência de monômeros disponíveis. A facilitação a nutrientes prontamente assimilados está relacionada à repressão catabólica de muitos fungos, relacionada provavelmente com a economia de energia (Piscitelli et al., 2011).

Conforme Simões (2015), para a formação de corpos frutíferos torna-se necessário garantir a distribuição do inóculo ao substrato acrescentando-se cerca de $1-5 \%$ de massa do substrato em inóculo. Esta quantidade possibilitou crescimento micelial uniforme mesmo em substrato não suplementado e em ausência de reguladores de $\mathrm{pH}$. O tempo de colonização obtido no estudo também foram encontrados por Eira e Bueno (2005), até a completa colonização das sementes pelo micélio fúngico compreendido de
20-25 dias em que foi realizado a pesquisa dentro da conformidade.

\section{Obtenção do inóculo (Spawn)}

A figura 1 apresenta a disseminação do micélio colonizado ao decorrer de 24 dias, referente às linhagens de POP e POB, bem como as características de colonização perante a mesma condição ambiental de desenvolvimento.

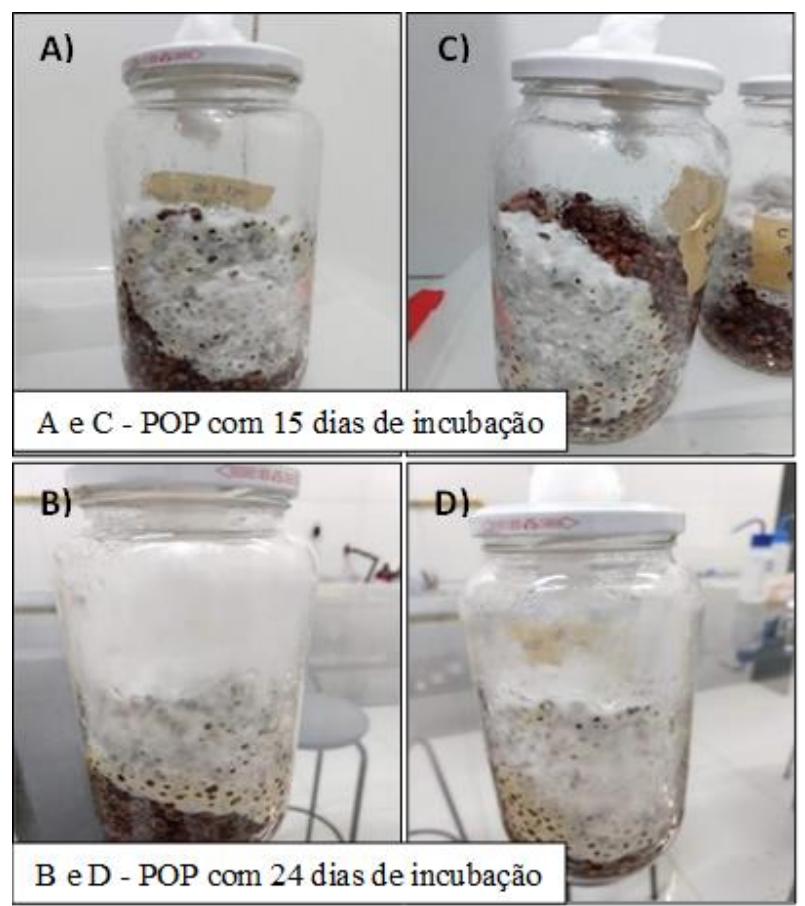

Figura 1 - Variação de crescimento micelial, no mesmo substrato nas mesmas condições de desenvolvimento do fungo Pleurotus ostreatus

\section{Monitoramento de desenvolvimento do micélio}

Após o preenchimento dos vasos, esterilização e a respectiva inoculação do spawn, deu início ao monitoramento do micélio nos vasos a partir da visualização aparente de assimilação das hifas no substrato.

Em relação ao tempo de colonização do meio, de forma geral, o crescimento micelial da cepa foi menor que os 30 dias estipulados. Esta característica é muito favorável, pois com o tempo de colonização inferior reduz-se o risco de contaminação e o período de incubação e formação de basidiomas, tornando a produção mais promissora (Marino et al., 2008).

De acordo com Albuquerque (2010), de forma geral o primeiro fluxo é o mais expressivo em relação à massa de cogumelos colhidos, sendo o primeiro pico produtivo a etapa que representa $50 \%$ da produtividade total. Porém, quanto referente ao ponto de vista de produção, a soma 
dos fluxos pode aumentar consideravelmente a quantidade de rendimento do substrato, visto que este pode ter até 3 fluxos de frutificação. A figura
2 apresenta dados referentes ao período de incubação, primórdios, frutificação, colheita e duração de cultivo em frascos de vidro.

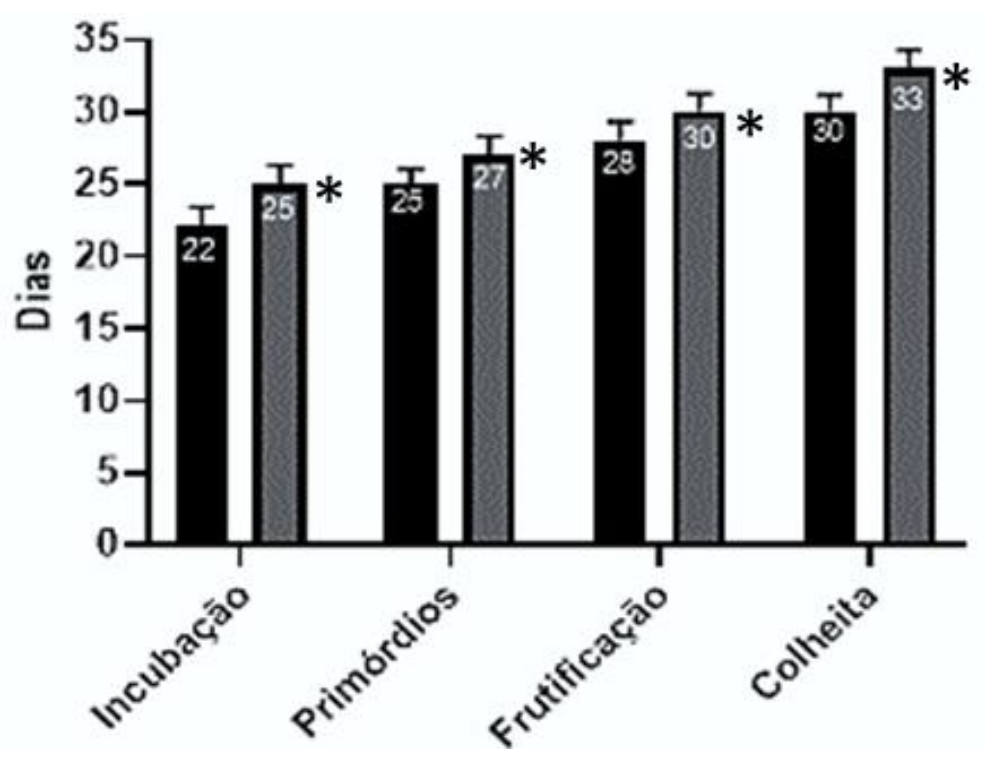

Cultivo de POP. *Cultivo de POB

Figura 2 - Tempo entre a colonização e colheita de (POB e POP) do gênero $P$. ostreatus cultivados em bagaço de cana-de-açúcar e raspas de madeira

Referente ao monitoramento da colonização observou-se que o desenvolvimento dos substratos diferiu quanto à capacidade de assimilação das hifas. Atingiram-se valores médios entre as linhagens, conferindo 22 dias e 25 dias para POP e $\mathrm{POB}$, respectivamente, quanto ao cultivo em frasco de vidro, o mesmo já não se obteve em relação ao cultivo em sacos contendo 10 e $5 \mathrm{~kg}$ de substrato nas mesmas condições de crescimento.

Tavares (2015), realizou ensaios de cultivo de Pleurotus com vários substratos, dentre eles, a palha de feijão em $60 \%$ e bagaço de cana-deaçúcar com $40 \%$ da concentração, obteve-se como tempo de colonização de 15 a 21 dias e frutificação com 22 a 26 dias. Tais valores se aproximam dos resultados encontrados no presente estudo, porém cabe destacar a diferença da composição dos substratos.

Os substratos de POP e POB foram analisados ao mesmo tempo e comparados quanto a sua eficiência e adaptação. Pode observar que de forma geral apresentaram crescimento semelhante para as linhagens como mostra a figura 3.

A proliferação do micélio foi observada $72 \mathrm{~h}$ após inoculação como mostra a figura $\mathrm{A}$ e $\mathrm{B}$, e finalizada com tempo médio de 30 dias para todos os tratamentos visando a completa colonização dos substratos. De acordo com Mantovani e colaboradores (2012), o produtor deve estar atento as fases de cultivo visto que podem apresentar metabolismo e preferências diferentes de acordo com a linhagem escolhida, ocasionando uma flutuação da produtividade.

Segundo Minotto et al., (2011), a assimilação dos microrganismos aos meios de cultivo ocorre em função da disponibilidade de nutrientes, destacados principalmente em fontes de carbono, nitrogênio e do seu potencial genético. A composição do substrato tornou propícia a produção de cogumelos ao longo do processo, ainda que sejam observadas mudanças sutis sobre a relação carbono por nitrogênio do substrato. Estas mudanças não conferem consequências ao resultado de um processo de compostagem curta, no qual não há necessidade de biotransformação profunda da matéria orgânica, tendo em vista que o composto foi preparado especificamente para o cultivo de $P$. ostreatus.

Vale ressaltar que os sacos dispostos com maior quantidade de substrato foram sujeitos a contaminação visto o aumento no tempo de colonização. Uma vez que, como já relatado por Silva et al., (2005), a não colonização do micélio influência na produção de cogumelos. Em contrapartida, quanto à utilização dos frascos de vidro não se observou contaminantes durante todo o ciclo, o qual favoreceu sua utilização. 


\section{A)}

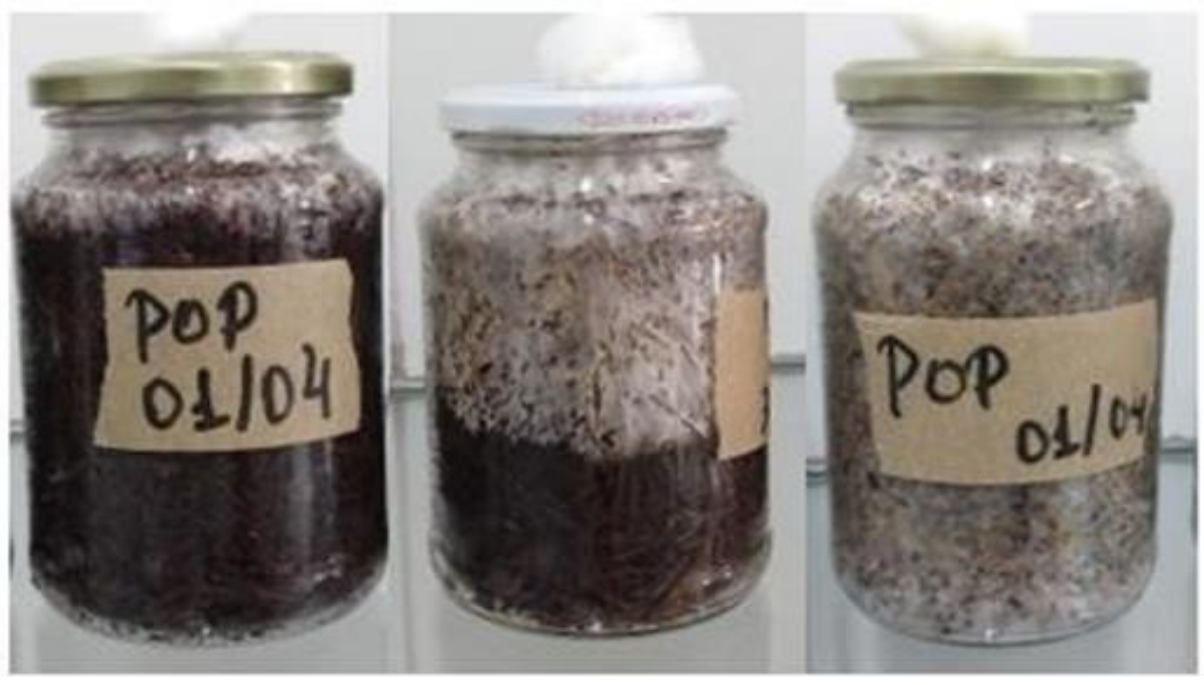

B)

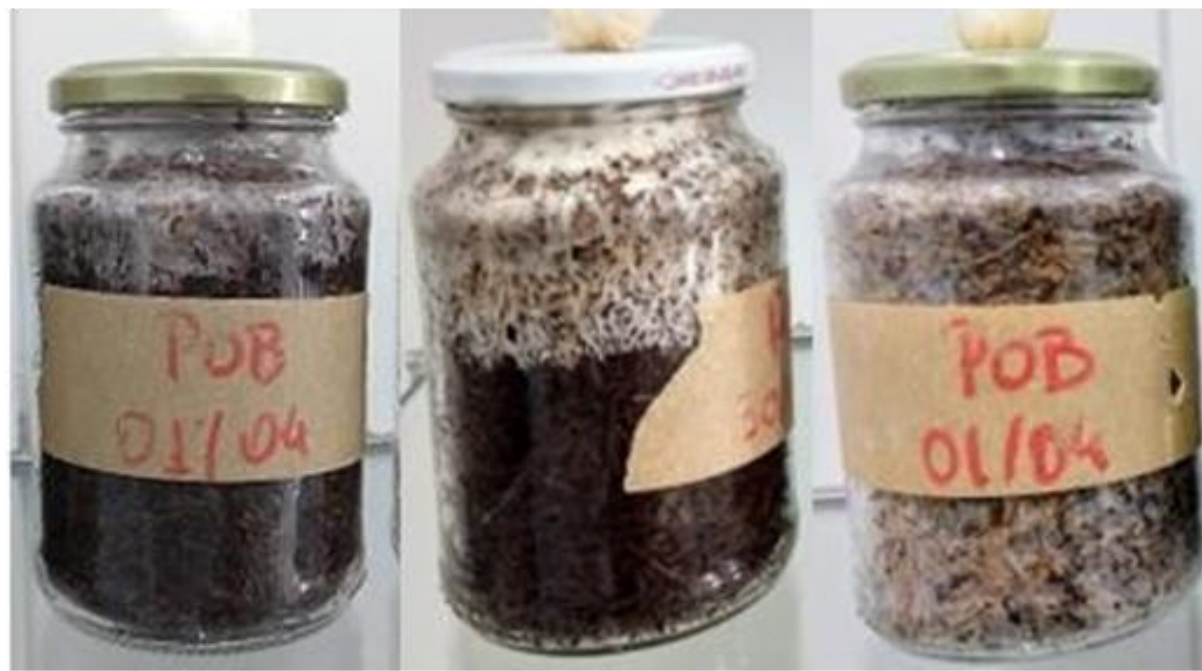

A - Crescimento do micélio com linhagem de POP em 72 horas, 14 dias e 24 dias. B - Crescimento do micélio com linhagem de POB em 72 horas, 14 dias e 27 dias.

Figura 3 - Frascos contendo linhagens de POP e POB

\section{Produção e Eficiência Biológica}

A figura 4 apresenta os níveis de eficiência biológica referente à colheita dos diferentes frascos de vidro contendo as linhagens de POP e $\mathrm{POB}$, o qual expressa a relação entre a massa fresca de cogumelo sobre a massa seca de substrato.

Para Siqueira et al., (2011), a eficiência biológica é um método eficaz para avaliar a eficiência da bioconversão do substrato em cogumelos. Contudo, para os produtores de cogumelos, o parâmetro mais prático é o rendimento. Mediante a isto, um bom índice de rendimento/produtividade inicia com valores superiores à $10 \%$ referente ao peso de cogumelos frescos em relação ao substrato úmido. 


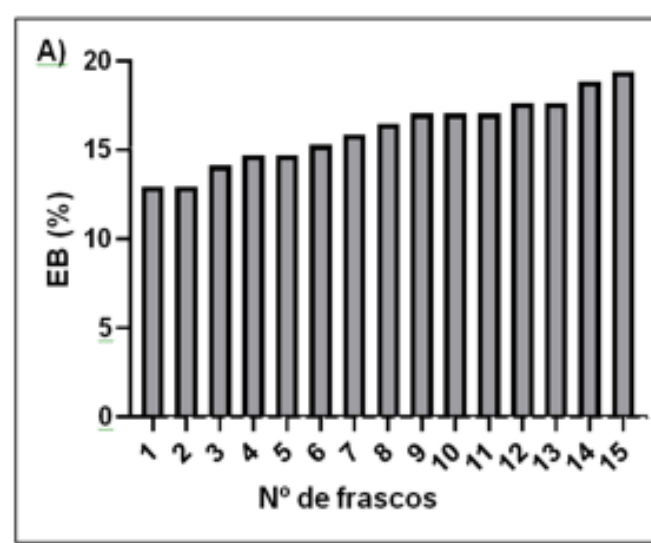

A - Eficiência biológica de $P$. ostreatus preto (POP) em frascos de vidro

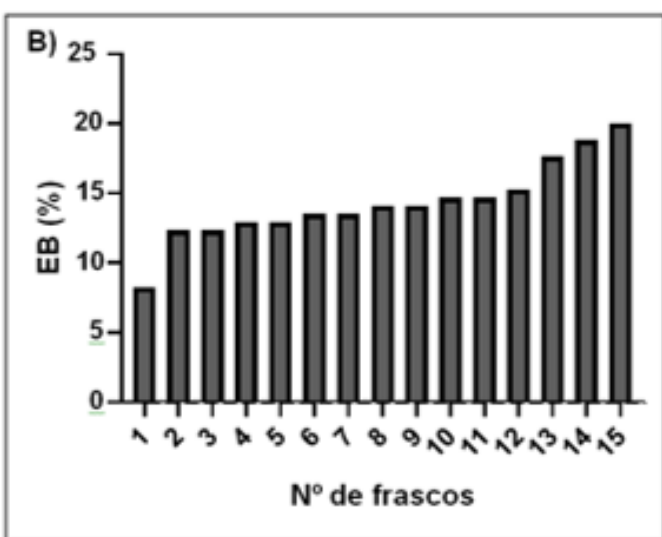

B - Eficiência biológica de $P$. ostreatus branco (POB) em frascos de vidro

Figura 4 - Eficiência Biológica (EB) de POP e POB, obtido a partir da produção do cogumelo fresco, em relação ao peso seco do substrato utilizado. $\mathrm{EB}=$ ([peso fresco de cogumelos/peso seco do substrato inicial] $\mathrm{x}$ 100)

O estudo de Ramos et al, (2011), avaliaram o crescimento da espécie $P$. ostreatus em atmosfera controlada e encontrou valor médio de produção de $13,74 \%$ de EB e $6,8 \%$ referente a produtividade, cultivados em palha de trigo e colocadas em sacos de polipropileno.

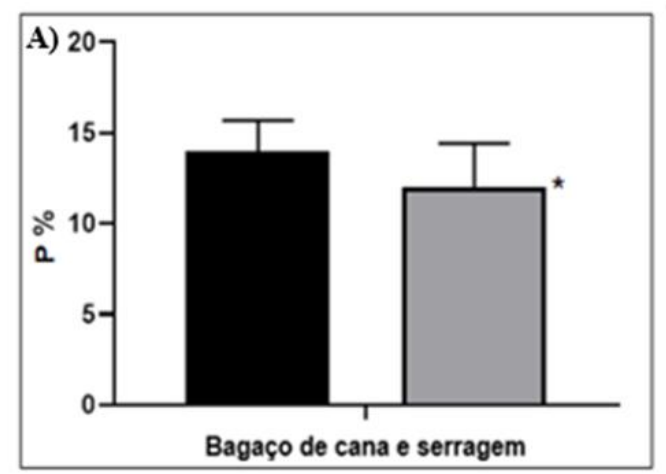

$P$. ostreatus preto-POP
Valores que comparados ao cultivo em frasco apresentam diferenças significativas no acréscimo de produção e EB, visto que em ambas as linhagens em cultivo foram superiores à média de $10 \%$.

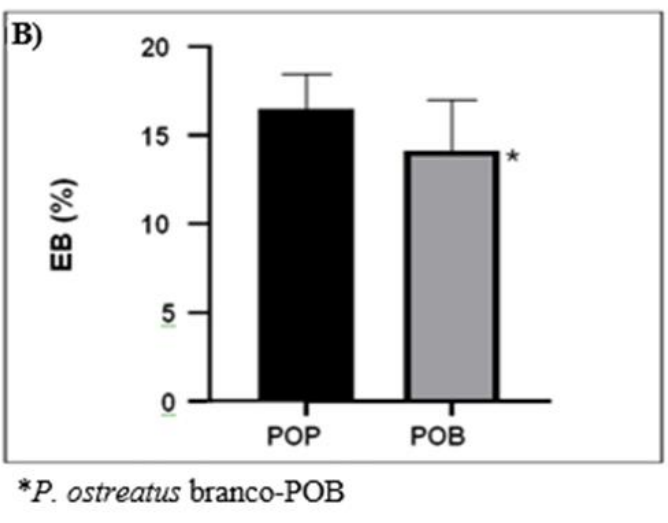

Figura 5 - Apresenta respectivamente os valores médios obtidos da produtividade e eficiência biológica de cogumelos das linhagens do género $P$. ostreatus

Houve, neste caso, produtividade próxima tanto para POP e POB, porém a linhagem POP obteve valores de média de produção com margem de $14 \%$ referente a produtividade como mostra a figura 5-A, nas condições ambientais propostas esta linhagem apresentou-se mais produtiva e com maior capacidade de bioconversão do substrato.

Quanto ao cultivo em sacos obteve-se 166 e $364 \mathrm{~g}$ de $\mathrm{POB}$ para os substratos contendo 5 e 10 $\mathrm{kg}$ respectivamente, quanto aos valores de POP $170 \mathrm{~g}$ referente a $5 \mathrm{~kg}$ e posteriormente $492 \mathrm{~g}$ de $10 \mathrm{~kg}$. Observou-se que o micélio necessitou de maior tempo de colonização visto o breve período de incubação ou a distribuição não satisfatória referente a quantidade de spawn utilizada, apresentando dificuldade de total colonização do substrato.

Relacionado aos valores de eficiência biológica dispostos na figura 5-B, foi obtido valores de $16,11 \%$ para o cultivo de POP e $14,11 \%$ referente ao cultivo de $\mathrm{POB}$, próximos aos encontrados pela pesquisa desenvolvida por Paz e colaboradores (2006), o qual, a partir do cultivo do gênero Pleurotus em bagaço de uva, resultante da indústria de vinhos e bagaço de maçã, resultante da indústria de sucos (Breyer et al., 2007), obtiveram rendimento de cogumelos nos valores de $15,23 \%$ para uva e $16,57 \%$ para maçã, em clima temperado. 


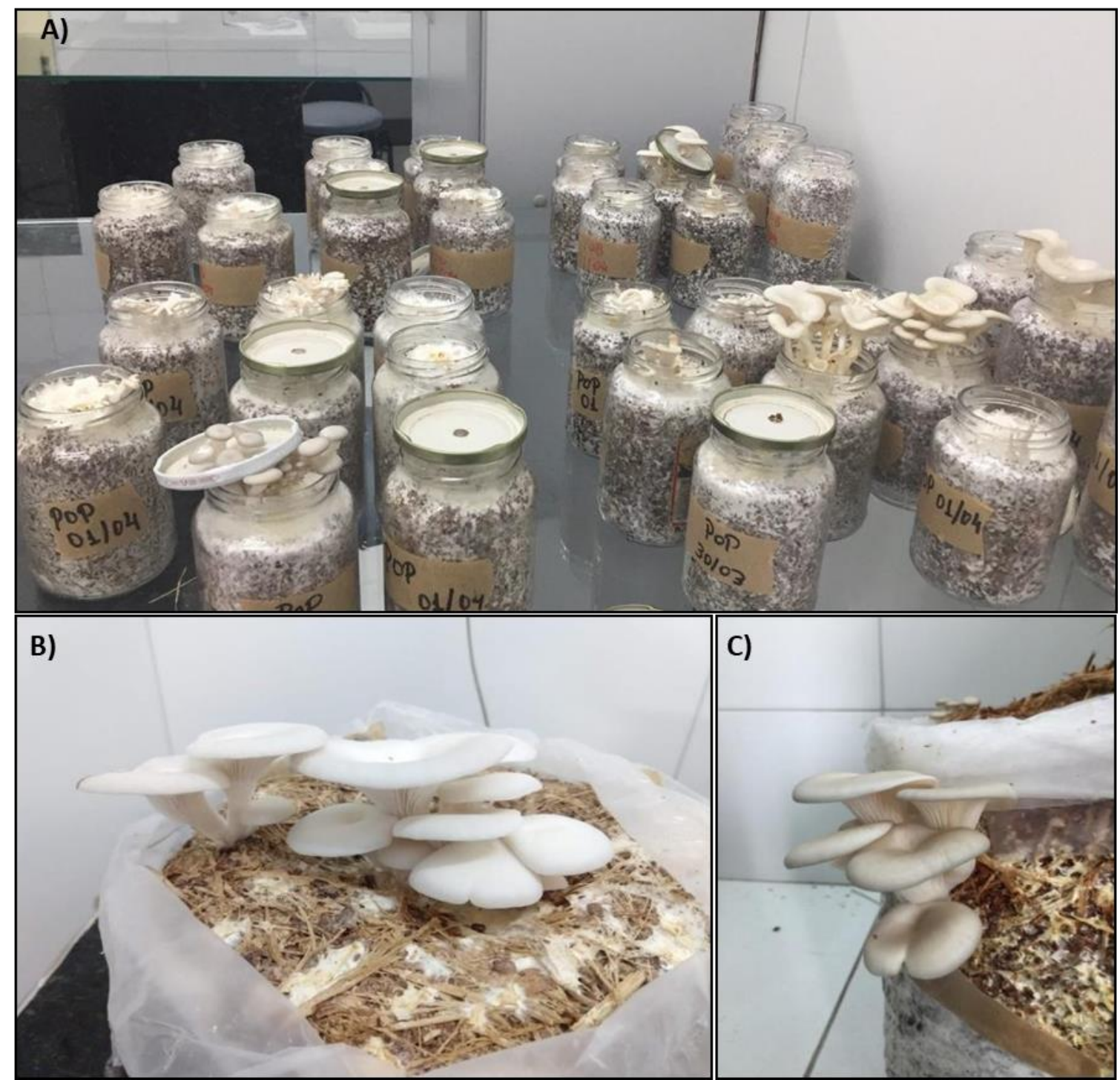

A - Disposição de frascos evidenciando os primórdios de frutificação. B - Corpos frutíferos de POB em saco de polietileno. C - Corpos frutíferos de POP em saco de polietileno.

Figura 6 - Linhagens de POP e POB durante o período de frutificação no substrato padronizado

Assim, no presente estudo, vários fatores podem ter levado a esses valores de EB e rendimento de forma geral. Um desses fatores é a temperatura, dado que, dentro de uma mesma espécie, cada linhagem pode requerer uma faixa de temperatura diferente, apesar de crescerem em uma ampla faixa, é possível que em temperaturas altas, nas quais a linhagem de $P$. ostreatus desse experimento foi produzida, não sejam as ideais para uma maior produtividade.

Sales-Campos et al., (2008) testando o crescimento micelial de isolado de $P$. ostreatus, em meios de culturas diferentes, nas temperaturas de 22 até $30^{\circ} \mathrm{C}$ e posteriormente até $35^{\circ} \mathrm{C}$, observaram que a 30 e $35^{\circ} \mathrm{C}$, o crescimento foi afetado, sendo o melhor resultado de crescimento obtido a $25^{\circ} \mathrm{C}$.

A composição química do substrato testado, bem como a disponibilidade de componentes no resíduo, pode ser de difícil decomposição pelo fungo e ocasionar influência direta na $\mathrm{EB}$, sendo essencial a presença de açúcares prontamente assimiláveis (Pedra e Marino, 2006; Cardoso et al., 2013).

Gyenge etal., (2016) observaram características distintas em relação ao cultivo em sacos e ao cultivo em frascos, concluíram que a tecnologia de cultivo, bem como a embalagem também pode influenciar na EB e rendimento. Dentre estas, o uso de frascos permitiu a reutilização em diversos cultivos e maior eficiência biológica, apresentando cogumelos mais uniformes, enquanto que nos sacos, permitiram uma única utilização e a sua posterior formação de resíduo (lixo), a eficiência biológica foi menor, bem como os valores obtidos.

Colavolpe et al. (2014), utilizaram a 
esterilização em autoclave, imersão em água quente e gesso $\left(\mathrm{CaSO}_{4} \cdot 0,5 \mathrm{H}_{2} \mathrm{O}\right)$, utilizando a mesma metodologia de cultivo. Segundo os autores, ajustar o $\mathrm{pH}$ do substrato para níveis alcalinos é uma boa forma de inibir o crescimento de contaminantes, sem afetar o crescimento de $P$. ostreatus.

\section{Composto Exaurido}

A utilização do substrato pós-cultivo de $P$. ostreatus possui sua eficácia como fertilizante e condicionador do solo (Medina et al., 2012; Oda et al., 2014) e como substrato para produção de mudas (Silva et al., 2005) avaliada positivamente neste meio. Segundo Nakatsuka et al. (2016) a adição de substrato pós-cultivo fresco promove a atividade biológica do solo e do subsolo. Estes autores recomendaram a adição de substrato póscultivo de cogumelos como uma prática para a melhoria da estrutura do solo em regiões subtropicais.

A utilização de resíduos lignocelulósicos para a produção de cogumelos pode ser vantajosa para reduzir o impacto ambiental destes resíduos, agregar valor econômico com a produção de alimento de alto valor nutricional para os seres humanos e ainda permitir a utilização de tais resíduos como fertilizantes (Bento et al., 2014).

Diante disso, a utilização dos resíduos de bagaço da cana-de-açúcar e raspas de madeira como substrato para a produção de cogumelos comestíveis e o aproveitamento do substrato póscultivo como adubo e fertilizante do solo, apresenta-se como uma alternativa viável, tanto do ponto de vista econômico, como ambiental e social.

\section{CONCLUSÕES}

A técnica e os tratamentos utilizados (calcário dolomítico e gesso) em resíduos madeireiros e agrícolas como substrato para cultivo de $P$. ostreatus, apresentaram boa taxa de produção, com obtenção de corpos de frutificação em todos os ensaios de produção.

Observamos que o cultivo em frascos de vidro reutilizáveis proporcionou melhores médias quando comparado à utilização de sacos de polipropileno. Mediante ao ponto de vista produtivo e ecológico, a utilização dos frascos colaborou com a colonização do substrato e obtenção de corpos frutíferos, além de diminuir a projeção de dejetos e assim reduzir um possível impacto ambiental.

Neste sentido, tornam-se necessárias novas pesquisas considerando avaliar a adaptação dessas linhagens as altas temperaturas locais para que a técnica se aproxime ainda mais de produtores, bem como a utilização de suplementos para melhorar a disponibilidade de nutrientes e garantir não só uma boa produção, mas também um alimento rico quanto às suas características nutricionais, além de avaliar a aceitação local mediante a sua inserção como produto alimentício ou atividade de comércio.

\section{REFERÊNCIAS BIBLIOGRÁFICAS}

Albuquerque MP. Cultivo de Lentinus sajor-caju Pleurotus sajor- caju e Pleurotus spp. em diferentes substratos. Ano de obtenção: 2010. 126 P. Tese (Doutorado em Agricultura familiar) - Universidade Federal de Pelotas, Rio Grande do Sul.

Alexandrino AM, Faria HG, Souza, CGM, Peralta, RM. Aproveitamento do resíduo de laranja para a produção de enzimas lignocelulolíticas por Pleurotus ostreatus (Jack:Fr). Ciência Tecnologia Alimentar, v.27, n.2, p.364368, 2007. https://doi.org/10.1590/S010120612007000200026

Bento CBP, Da Silva JS, Rodrigues MT, Kasuya MCM, Mantovani HC. Influence of white-rot fungi on chemical composition and in vitro digestibility of lignocellulosic agro-industrial residues. Afr. J. Microbiol. Res, v.8, n.28, p.2724-2732, 2014.

https://doi.org/10.5897/AJMR2014.6858

Burgi, R. Utilização de resíduos culturais e de beneficiamento na alimentação de bovinos. Anais do $6^{\circ}$ simpósio sobre nutrição de bovinos da FEALQ, 1995. Piracicaba SP, p.153-169.

Breyer CA, Paz MF, Giovanni RN. Cultivo de Pleurotus sajor-caju em bagaço de maçã pela técnica Jun-Cao. In: Simpósio Nacional de Bioprocessos, 16, 2007, Curitiba. Anais. Curitiba, 2007.

Cardoso JCP, Demenjour P, Louis MM, Paz MF. Cultivo do cogumelo comestível Pleurotus ostreatus em bagaço de bocaiuva e de cana-de-açúcar pela técnica JUN-CAO. Evidência, v.13, n.1, p.31-40, 2013.

Chang Shu-Ting, Miles P. Mushrooms: Cultivation, Nutritional Value, Medicinal Effect and Environmental Impact. CRC Press: USA, 478p. 2004.

Cheung PCK. The nutritional and health benefits of mushrooms. British Nutrition Foundation Nutrition Bulletin, v.35, n.4, p.292-299, 2010. https://doi.org/10.1111/j.14673010.2010.01859.x

Colavolpe MB, Mejía SJ, Albertó E. Efficiency of treatments for controlling Trichoderma spp during spawning in cultivation of lignicolous mushrooms. Brazilian Journal of Microbiology, v.45, n.4, p.1263-1270, 2014. https://doi.org/10.1590/S1517-83822014000400017.

Eira AF, Bueno FS. Cultivo de cogumelo: shimeji e hiratake. Viçosa: CPT, 224p. 2005.

Eira AF, Esposito E, Azevedo JL. Fungos uma introdução à biologia, bioquímica e biotecnologia. Caxias do Sul: Educs, 638p. 2004.

Fernandes Â, Barros L, Martins A, Hebert P, Ferreira ICFR. Nutritional characterisation of Pleurotus ostreatus (Jacq. 
ex Fr.) P. Kumm. produced using paper scraps as substrate. Food Chemistry, v.169, p.396-400,2015.

https://doi.org/10.1016/j.foodchem.2014.08.027

Furlani RPZ, Godoy HT. Nutritional value of edible mushrooms. Ciência e Tecnologia de Alimentos, v.27, n.1, p.154-157, 2007.

Gyenge B, Kozma T, Almádi B, Szarvas J, Villás G, Urvölgyi M. Technology innovation in sustainable growing and distribution of king oyster mushroom. Hungarian Agricultural Engineering, v.29, p.5-10. 2016. https://doi.org/10.17676/HAE.2016.29.5

Lopes S, Rosso S. Bio. São Paulo: Editora Saraiva, 784 p.2013.

Machuca A, Ferraz A. Hydrolytic and oxidative enzymes produced by white- and brown-rot fungi during Eucalyptus grandis decay in solid medium. Enzyme Microbial Technology, v.29, n.6, p.386-391, 2001. https://doi.org/10.1016/S0141-0229(01)00417-3

Marino RH, Abreu LD, Mesquita JB, Ribeiro GT. Crescimento e cultivo de diferentes isolados de Pleurotus ostreatus (Jacq.: fr.) Kummer em serragem da casca de coco. Arq. Inst. Biol, v.75, n.1, p.29-36,2008.

Mantovani TRD, Meirelles P, Valle JS, Linde GA, Colauto NB. Formulação de substratos na produção de biomassa micelial e de lacase de Pleurotus ostreatus. Semin Agrar. v.33, n.5, p.1681-92, 2012.

Menezes CR, Barreto AR. Biodegradação de resíduos lignocelulósicos por fungos basidiomicetos: Caracterização dos resíduos e estudo do complexo enzimático fúngico. Revista Eletrônica em Gestão, Educação e Tecnologia Ambiental, v.19, n.2, p.1365-1391, 2015.

Medina E, Paredes C, Bustamante M, Moral Raúl, MorenoCaselles J. Relationships between soil physico-chemical, chemical and biological properties in a soil amended with spent mushroom substrate. Geoderma, v.173, n.174, p.152$161,2012$.

https://doi.org/10.1016/j.geoderma.2011.12.011.

Minotto E, Bernardi E, Rosa FO, Nascimento JS. Desenvolvimento micelial in vitro de Pleurotus sp. Em palha de arroz suplementada com serragem de couro. Arquivo do Instituto Biológico, v.78, n.4,p.609-613,2011.

Moda EM, Horri J, Spoto MHF. Edible mushroom Pleurotus sajor-caju production on washed and suplemented sugarcane bagasse. Scientia Agrícola, Piracicaba, v.62, p.127132, 2005. https://doi.org/10.1590/S010390162005000200006

Nakatsuka H, Oda M, Hayashi Y, Tamura K. Effects of fresh spent mushroom substrate of Pleurotus ostreatus on soil micromorphology in Brazil. Geoderma. v.269, p.54-60, 2016. https://doi.org/10.1016/j.geoderma.2016.01.023

Oda M, Tamura K, Nakatsuka H, Nakata M, Hayashi Y. Application of high carbon: nitrogen material enhanced the formation of the soil a horizon and nitrogen fixation in a tropical agricultural field. Agricultural Sciences, v.5, n.2, p. $1172-1181,2014$. http://dx.doi.org/10.4236/as.2014.512127

Paz MF, Vieira E, Breyer CA, Giovanni RN, Bertoldi FC Cultivo de Pleurotus sajor-caju em bagaço de uva Isabel. Evidência, v.6, p.187-194, 2006.
Pedra WN, Marino RH. Cultivo axênico de Pleurotus spp. em serragem da casca de coco (Cocos nucifera linn.) suplementada com farelo de arroz e/ou de trigo. Arquivos do Instituto Biológico, v.73, n.2, p.219-225, 2006.

Pelizer LH, Pontieri MH, Moraes IO. Utilização de resíduos agro-industriais em processos biotecnológicos como perspectiva de redução de impacto ambiental. Journal of Technology Management and Innovation, v.2, n,1, p.118-127, 2007.

Piscitelli A, Giardina P, Lettera V, Pezzella C, Sannia G, Faraco V. Induction and transcriptional regulation of laccases in fungi. Current Genomics, v.12, n.2, p.104-112, 2011. https://doi.org/10.2174/138920211795564331

Ramos C, Sapata M, Ferreira A, Andrada L. Candeias, M. Produção de três espécies de cogumelos Pleurotus e avaliação da qualidade em atmosfera modificada. Revista de Ciências Agrarias, v.34, n.1, p.57-64, 2011.

Sales-Campos C, Eira AF, Jesus MA, Campagnolli F, Andrade MCN. Crescimento micelial de Pleurotus ostreatus em resíduo de Simarouba amara. Pesq. Agropec. Bras, v.43, n.11, p.1633-1635, 2008. https://doi.org/10.1590/S0100-204X2008001100024

Sánchez C. Bioactives from Mushroom and Their Application BT - Food Bioactives: Extraction and Biotechnology Applications. In: Puri M. (Ed.). Cham: Springer International Publishing, p.23-57, 2017.

Simões MG. Desenvolvimento e crescimento da espécie de cogumelo Pleurotus ostreatus em garrafas de plástico reutilizado. Ano de obtenção: 2015. 114 p. Dissertação (Mestrado em Tecnologia e Segurança Alimentar) Universidade dos Açores, Angra do Heroísmo, Portugal.

Silva GA, Trufem SFB. Saggin Júnior OJ, Maia LC. Arbuscular mycorrhizal fungi in a semiarid copper mining area in Brazil. Mycorrhiza, v.15, p.47-53, 2005. https://doi.org/10.1007/s00572-004-0293-6

Siqueira FG, Martos ET, Silva R, Dias ES. Cultivation of Pleurotus sajor-caju on banana stalk and Bahia grass-based substrates. Horticultura Brasileira, v.29, n.2, p.199-204, 2011. https://doi.org/10.1590/S0102-05362011000200011

Tavares ACD. Cultivo do cogumelo comestível Pleurotus ostreatus INPA 1467: Produção, composição centesimal e mineral. Ano de obtenção: 2015. 91p. Dissertação (Mestrado em Biotecnologia) - Universidade Federal do Amazonas, Manaus. 